\title{
ÓRGANOS DE LA ADMINISTRACIÓN TRIBUTARIA PERUANA
}

CPC. LEONCIOJAVIER MELGAREJO(*)

\section{AVANCES Y RETROCESOS EVOLUTIVOS}

En la historia peruana se han dictado numerosas normas fiscales, no solamente para crear, modificar, inafectar o extinguir tributos, sino también se ha venido implementando diferentes formas y denominaciones a la Administración Tributaria.

Nace en 1818, con la denominación del Departamento de Contribuciones Directas, Correos y Papel Sellado y luego de una vigencia de treinta años en el Gobierno de don Ramón Castilla (1848), al crearse la Dirección General de la Hacienda, cambia de nombre de Oficina de Contribuciones, Correos y Papel Sellado; paralelamente a las oficinas:

- Oficina de Aduanas y de la Cuenta General de la República

- Oficina de Crédito Público

- Oficina de Moneda y Rentas de Guano

En 1855, al reorganizarse el Sector de la Hacienda y Comercio, se implementaron cuatro Direcciones:

- Dirección de Administración General

- Dirección de Crédito

- Dirección de Contabilidad

- Dirección de Contribuciones
Para luego implementarse (en 1858) esta última Dirección en tres secciones:

- Sección del Guano

- Sección de Aduanas

- Sección de Contribuciones

En 1876, se denominó como Departamento de Contribuciones y Bienes Nacionales para que en 1916, después de 40 años nuevamente se categorice con el nombre de Dirección de Aduanas y Contribuciones hasta la reforma del sector Hacienda, en 1920 , en que se incrementaron sus atribuciones, simplificándose su nombre en Dirección de Contribuciones:

- Proponer al gobierno las reformas convenientes de su sector

- Dar cuenta anualmente del movimiento de los impuestos

- Llevar estadística del consumo de los bienes gravados

Al dictarse la Ley 7904 (1933), época de grandes cambios tributarios, se denominó como Superintendencia General de Contribuciones, con una organización a nivel nacional, estableciéndose sus oficinas departamentales y provinciales para la administración y acotación de impuestos directos, así como la de fiscalizar los impuestos indirectos. Más adelante en 1968, se retornó a su anterior denominación de Dirección General de Contribuciones.

(*) Docente Asociado y Director de Asuntos Administrativos de la Facultad de Ciencias Contables de la UNMSM 
Hasta el año 1988 era un órgano de línea administrativa y económica del Ministerio de Economía y Finanzas, hasta que mediante Ley $24829(07 / 06 / 88)$ y los Decretos Legislativos 500 y 501 (29/11/88) se crearon: la Superintendencia Nacional de Aduanas-ADUANAS (para la administración de tributos externos: importación y exportación) y la Superintendencia Nacional de Administración Tributaria-SUNAT (para la administración de impuestos internos), respectivamente. Según la Constitución ambas instituciones de carácter público y con autonomía administrativa y económica no estuvieron establecidas dentro de la estructura orgánica.

A partir de 1991 comienza la reforma estructural de la Administración Tributaria, con implementaciones propias tanto en la logística como principalmente de los recursos humanos, especialmente seleccionados; $y$ ubicados en la ley laboral del sector privado (Ley 4910).

Participaron en su implementación profesionales del Banco Central de Reserva del Perú, los expertos enviados por organismos internacionales tales como el FMI (Fondo Monetario Internacional), BID (Banco Interamericano de Desarrollo) y el CIAT (Centro Interamericano de Administradores Tributarios), así como dotación de una considerable logística física y de equipos.

\section{RECURSOS FINANCIEROS ASIGNADOS}

Corresponden como recursos de la Superintendencia Nacional de Administración Tributaria-SUNAT, los siguientes presupuestos:

- $2 \%$ de la recaudación de tributos administrados por ésta.
- $25 \%$ del producto de los remates de bienes embargados y/o decomisados

- $0.2 \%$ de la recaudación de los tributos cuya administración se le encarga, que no constituyen rentas del Tesoro Público.

Asimismo, corresponden como recursos financieros de la Superintendencia Nacional de Aduanas -SUNAD-ADUANAS:

- 3\% del total del ingreso tributario que recauda ADUANAS para el Tesoro Público.

-50\% del producto del producto del remate de mercancías, caídas en abandono legal y comiso administrativo.

-Los ingresos propios generados por los servicios que presta.

- Las rentas generadas por los depósitos de sus ingresos propios en el sistema financiero.

-Los legados, donaciones, transferencias y otros recursos provenientes de cooperación internacional.

Según la ley del Presupuesto General de la República se establece de manera especial, con naturaleza de las empresas del Estado. Además, está normado: "Que tanto la SUNAT y SUNAD-ADUANAS, depositarán en la cuenta principal del Tesoro Público, solamente la diferencia entre sus ingresos y egresos trimestrales".

\section{LA ADMINISTRACIÓN TRIBUTARIA Y LA CONSTITUCIÓN POLITICA DEL PERÚ}

Trataré de referirme solamente a las dos últimas constituciones políticas del Estado Peruano para poder analizar la esencia Constitucional de la Tributación en el Perú: 
La Constitución de 1979, promulgada por la Asamblea Constituyente del 12 de julio de 1979, establece primero la obligación del Estado para luego fijar sus atribuciones de crear tributos; tal como reza en sus diferentes párrafos que pone en primacía los derechos $\mathrm{u}$ atenciones a la sociedad y por ende a los señores contribuyentes:

- Que "al Estado le corresponde promover las condiciones económicas y sociales".

-"Eliminar la pobreza y asegurar por igual a los habitantes de la República".

-Que "sólo por ley expresa se crean, modifican o suprimen tributos y se conceden exoneraciones y otros beneficios tributarios".

-Que "la tributación se rige por los principios de legalidad, uniformidad, justicia, pubhcidad, obligatoriedad, certeza y economía en la recaudación. No hay impuesto confiscatorio ni privilegio personal en materia tributaria".

-Que "también los gobiernos regionales pueden crear, modificar y suprimir tributos o exonerar de ellos, con arreglo a las facultades que se les delegan por ley".

-Así como, "los gobiernos locales pueden crear, modificar o suprimir contribuciones, arbitrios y derechos a exonerar de ellos conforme a ley".

La Constitución Política de 1993 (vigente) considera:

- Que "la defensa y la dignidad humana son fines supremos del Estado y la Sociedad, así como a la igualdad ante la ley, que nadie puede ser discriminado".

- Que "el Estado al ejercer la protesta tributaria debe respetar los principios de reserva de ley y los de igualdad y respeto a los derechos fundamentales de la persona".

- No hay prisión por deudas y ningún tributo puede tener efecto confiscatorio.

- Los tributos se crean, modifican o se derogan, así como se establece exoneración exclusivamente por Ley o Decreto Legislativo.

- Los aranceles y las tasas se regulan mediante Decreto Supremo.

- Los gobiernos locales pueden crear, modificar y suprimir contribuciones y tasas o exonerar de éstas con los limites que señala la ley.

La administración de la tributación nacional no está comprendida constitucionalmete dentro de la estructura orgánica del estado, ni tampoco ubicada entre los tres poderes del Estado, ni mucho menos en ninguna de estas constituciones "Ley de Leyes", refiere que en el Régimen de la Administración Tributaria es acreedora y los contribuyentes siendo los aportantes sean los deudores pero que así están implementados como tal en el Código Tributario. Se entiende tácitamente que para cumplir las obligaciones precitadas del Estado, la sociedad tiene la obligación de contribuir, pero está señalado primero la obligación del Estado y el derecho de las personas. Luego, por delegación de la sociedad personificado como ente jurídico y sufragado por los señores contribuyente está la contraprestación del Estado.

\section{DISCRIMINACIÓN ENTRE EL DEUDOR YACREEDOR TRIBUTARIO}

Las Normas Tributarias vigentes en el Perú discriminan relaciones entre las partes actuantes en el Derecho Tributario Peruano, implementados a favor de la Administración 
Tributaria mediante el Código y demás normas tributarias. Podemos citar:

- Ley Marco del Sistema Tributario Nacional. (Decreto Legislativo 771). establece que el Sistema Tributario Nacional se encuentra comprendido por el Código Tributario y los tributos ya sea del gobierno central o de gobiernos tocales, así como las contribuciones para organismos autónomos descentralizados.

-El Código Tributario (D.Leg. 816) vigente desde el 22/04/96 refiere: "Que la obligatoriedad tributaria, que es de derecho público, es el vínculo entre el acreedor y deudor tributario; establecido por la ley que tiene por objeto el cumplimiento de la prestación tributaria. Siendo exigible coactivamente.

-Que el gobierno central, los Gobiernos Regionales y los Gobiernos locales son acreedores de la obligación tributaria.

- El acreedor tributario a favor del cual debe realizarse la prestación tributaria.

- Son facultades de la Administración Tributaria la recaudación, determinación y fiscalización, aplicar medidas cautelares, inclusíve con presunciones de hechos gravables y la facultad discrecional de sancionar.

Mientras para el lado de los contribuyentes señala:

-Que "las personas naturales o jurídicas domiciliados en el Perú están sometidas al cumplimiento de las obligaciones tributarias".

-Que "el deudor tributario es la persona obligada al cumplimiento de la prestación tributaria como contribuyente o responsable".
-Que " las deudas tributarias gozan de privilegio general sobre todos los bienes del deudor tributario y tendrán preferencia sobre las demás obligaciones".

- Que "los deudores tributarios están obligados a facilitar las labores de fiscalización y determinación que realice la Administración Tributaria".

Así, entre los precitados, como las otras normas componentes del Código Tributario son explícitamente diferenciados, referidas a las obligaciones del deudor tributario o contribuyente, que inclusive se le considera como delincuentes comunes al ser castigados penalmente como es la implementación de la Ley Penal Tributaria (D.Ley. 813) y la Ley de Delito infracción tributaria (D.Leg. 815). Mientras, para la otra parte de la contienda tributaria osea para la Administración Tributaria, es decir para la Administración Tributaria se han implementado los tres poderes del Estado (normativo, ejecutivo y jurisdiccional); haciendo cada vez más poderoso y temerario.

\section{FACULTADES EXTRAORDINARIAS DE LA ADMINISTRACIÓN TRIBUTARIA}

Aparte de las atribuciones de recaudación y fiscalización, para la cual fue creada la Administración Tributaria, tiene otras facultades extraordinarias, estipuladas según el Código Tributario (vigente), Ley Penal Tributaria, Ley de Delito e Infracción Tributaria y demás normas implementadas para la Administración; entre ellas tenemos:

- Facultad de Presunción

- Facultad Discrecional

- Facultad de Reserva Tributaria

- Facutlad de Recabar y procesar denuncia penal

- Facultad de Recompensar

- Facultad de Sancionar 
Algunas facultades que constitucionalmente ni siquiera están establecidos, mucho menos para la Administración Tributaria pero, al amen gracias que otorga facultades el Poder Legislativo al Poder Ejecutivo se han implementado vía Decretos Legislativos.

La Administración Tributaria tiene la facultad discrecional de sancionar las infracciones que serán determinadas en forma objetiva, así como la acción de omisión de los deudores tributarios o terceros que violen las normas tributarias.

Cualquier persona puede denunciar ante la Administración Tributaria la existencia de actos que presumiblemente constituyan delitos tributarios y la Administración Tributaria de constatar hechos que "presumiblemente constituyan delito tributario o estén encaminados a este propósito", tienen la facultad discrecional de formular denuncia penal. Esto sin el requisito previo de culminación de fiscalización o verificación, tramitándose en forma paralela.

Son párrafos, entre otras facultades, que además de dictar normas, actar o autoacatar tributos, la fiscalización se extralimita hasta valiéndose de presunciones de personas particulares que denuncie a la Administración. Esta, sin la necesidad de concluír la vía administrativa, en uso de sus facultades discrecionales formularía proceso penal ante el Ministerio Público.

\section{BIBLIOGRAFÍA}

CONGRESO NACIONAL DE CONTADORES PÚBLICOS DEL PERÚ

1996. Trabajos sustentados. Huánuco,Perú.

CHÁVEZ ACKERMANN, Pascual

1996. "Impuesto a la renta"

DIARIOEL PERUANO

Normas Legales 1991-2000.

SUNAT

Publicaciones de la Gerencia de Comunicaciones y Relaciones Públicas -SUNAT.

VELÁSQUEZC., Juan

"Derecho tributario moderno". 